\title{
汀江岁月忆蔡师
}

周绍民*

厦门大学化学化工学院, 福建 厦门 361005

\section{Reminiscences of Tingjiang's Years and My Teacher Cai}

\section{Shaomin Zhou *}

College of Chemistry and Chemical Engineering, Xiamen University, Xiamen 361005, Fujian Province, China.

抗战时期, 厦门大学迁往长汀。我于1941年进入该校化学系(图1)。那时, 蔡启瑞先生是化学系 的讲师, 教过我 “定量分析化学” 和 “物理化学”。他在教学上的严谨和博学给我留下了深刻印象。

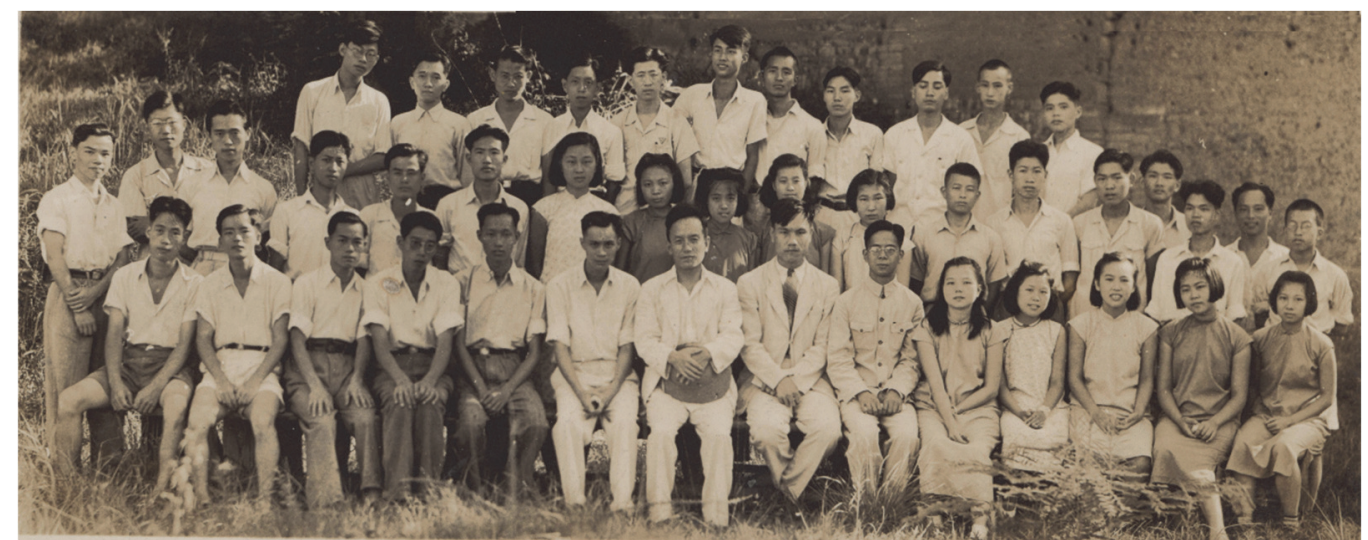

刘椽与化学系师生(1941-1944级)在长汀合影

前排: 左三周绍民、左六陈国珍、左七刘椽、左八蔡启瑞; 第二排: 左七朱沅、左八张永巽、左九刘藻琴、左十廖翔贞

1943年春, 大二下学期, 我开始接触到蔡先生的 “定量分析化学” 课程。课程要求实验结果误 差小于 $2 \%$, 如果超标, 必须重做。有一次, 我们分析铬铁矿样品, 按规定应该用坩埚做这个实验, 但当时供应室只有两只镍坩埚, 且每名同学必须同时做两份样品, 也就是说每次只能由一名同学进 行分析。为了让更多的学生能够尽快完成相关实验, 蔡先生建议改用铁坩埚试试, 还说: 铁坩埚便 宜, 数量较多, 但铁锈必须去除干净, 可以先高温加热, 然后放入水中急冷。几个同学都按照蔡先 生的小法尝试着。实验报告交上去后, 使用镍坩埚者达标得以通过; 反之, 凡用铁坩埚分析的, 都 没有满足误差的要求, 还得重来。第二轮依然是使用镍坩埚的成功了, 其他人照样通不过。因而, 纠结之处似乎已经真相大自, 我们心想这个实验大约可以告一段落矣。对此, 蔡老师说, 既然问题 出在铁坩埚上, 那么请你们用镍坩埚再做一遍。就这样, 不少同学接连做了三次实验, 每次费时一 整天，才最终宣告成功。这件70多年前的逸事我一直无法忘怀。 
1943年秋季, 我大三上学期的 “物理化学” 课由傅鹰教授主讲, 当时傅先生是教务长、知名教 授, 除了 “物理化学”之外, 还给我们上过低年级阶段的 “普通化学” 。傅教授只上完了 “物理化 学” 的上半部分, 就于1944年初离开了厦门大学, 下半部分由蔡启瑞先生接手。大家知道, “物理 化学” 是化学系的主课、重课, 能够让那时还只是讲师的蔡先生来救场, 反映了校系领导对他的信 任和器重。

当时, 系主任、教授上完课后, 大都各自忙于他们分管的工作，不会经常待在实验室；其他老 师课后一般待在实验室, 与学生接触比较多。那时, 蔡启瑞、陈国珍是讲师, 与学生打照面的机会 比教授多得多: 不管是实验中的异常现象还是难以解决的问题, 都可以向这两位请教。学习上的疑 惑, 无论是定量分析、物理化学, 还是无机化学、有机化学, 我们都可以得到他们的帮忙, 都会受 到认真对待, 他们总是尽量设法解决。所以, 我们和蔡先生的接触主要是在课外。最后一年做毕业 设计时, 我大多待在实验室, 遇到问题时最方便的办法是就近求助蔡先生。不止我这样, 几乎所有 同学均如此, 而且都能得到满意的答复, 获得有益的启发。所有这些都基于蔡老师对化学各个分 支一一有机、无机、分析、物化等一一的精深造诣和良好素养, 这时我们突然明白了萨本栋校长如此 欣赏他的理由。

我毕业后留校任教, 厦门大学也于抗战后搬回厦门。不久, 蔡启瑞先生负笈越洋深造, 再次返 回母校时, 他在结构化学、有机化学方面的功力又大大增强了, 为厦门大学物理化学整体实力进入 我国一流行列注入了力量。

蔡启瑞先生是1956年从美国回到厦门大学的, 此后, 在他的不解努力下, 我校的研究队伍不断 壮大, 研究水平也得到了显著的提高。当时, 我校和福建省科委合建了不少研究所, 包括化学一所、 化学二所等, 后来调整为科学院华东分院催化电化研究室, 蔡先生兼任该研究室主任。这些为后来 高校既是教学中心又是研究中心开创了条件。20世纪七八十年代, 蔡先生任我校副校长期间, 我在 他的领导下兼任科研处处长。经积极申请, 教育部批准我校组建物理化学研究所, 给了若干专职研 究名额。在此基础上, 化学化工学院的发展壮大有目共睹。为此, 我们不会忘记 “蔡启瑞” 这个光 辉的名字。 